\title{
Optimized seismic retrofit of steel-concrete composite buildings
}

Georgios S. Papavasileiou ${ }^{1}$, Dimos C. Charmpis ${ }^{2}$ and Nikos D. Lagaros ${ }^{3}$

${ }^{1}$ School of Architecture and Built Environment, University of Wolverhampton Wulfruna Street, Wolverhampton WV1 1LY, United Kingdom

G.Papavasileiou@wlv.ac.uk

${ }^{2}$ Department of Civil and Environmental Engineering, University of Cyprus 75 Kallipoleos Str., P.O. Box 20537, 1678 Nicosia, Cyprus charmpis@ucy.ac.cy

\footnotetext{
${ }^{3}$ Institute of Structural Analysis \& Antiseismic Research, School of Civil Engineering, National Technical University of Athens

9 Heroon Polytechniou Str., Zografou Campus, 15780 Athens, Greece nlagaros@central.ntua.gr
}

\begin{abstract}
This work is focused on comparatively assessing the cost-effectiveness of three seismic retrofit approaches for non-code-conforming frame buildings with steel-concrete composite columns. The first two of the assessed retrofit approaches aim in indirectly enhancing structural system performance by strengthening individual composite columns using reinforced concrete jackets or concrete-covered steel cages. The third retrofit approach considered aims in upgrading the composite building frame at hand by installing steel bracings at selected bays. A specially developed structural optimization procedure is used to perform an objective comparison of the cost-effectiveness of the three retrofit approaches. The objective of the optimization procedure is to minimize the total retrofit material cost, while constraints are imposed to ensure the satisfaction of design requirements for the retrofitted structure regarding member capacities (according to Eurocodes 3 and 4 for steel beams and composite columns, respectively), structural system performance under horizontal loading (based on interstorey drifts calculated by pushover analyses) and fundamental periods (obtained from eigenvalue analyses). By defining 30 cases of under-designed 2-storey, 4-storey and 6-storey composite buildings (i.e. buildings with steel-concrete composite columns), an extensive numerical investigation involving 120 retrofit optimization runs was conducted. The results obtained provide insight into the relative cost-effectiveness of the three seismic retrofit approaches and reveal certain conditions under which each approach is economically most viable.
\end{abstract}

Keywords: strengthening; concrete jacket; steel cage; steel bracing; cost-effectiveness; structural optimization. 


\section{Introduction}

Steel-concrete composite design has often been utilized for structures intended for long lifetimes in areas with considerable or even high seismicity. However, such buildings constructed some decades ago generally do not conform to the provisions of current design codes (especially of seismic codes), which are significantly more demanding than the guidelines that were available at the time of their construction. In order to improve these buildings' seismic performance, they need to be appropriately retrofitted. There are two main approaches to retrofit a structural system: (a) strengthening of existing deficient members of the system and (b) installation of additional elements in the system. For both approaches, numerous methods have been proposed, investigated and applied in practice. Even though most of these methods are already considered to be well established, research is still ongoing, in an effort to improve their efficiency or numerical modelling, while also new methods involving innovative materials and techniques are presented.

The first retrofit approach involves the enhancement of the structural behaviour of individual members, joints or specific areas of the structure; therefore, this can be considered as a local approach. Strengthening methods following this approach aim at increasing the flexural capacity, shear capacity or ductility of particular structural elements and, consequently, enhancing indirectly the seismic resistance of the overall structural system. Various relevant techniques can be found in the literature, with the most well-known being reinforced concrete jacketing, steel jacketing and confinement with Fibre Reinforced Polymers (FRP).

Reinforced concrete jacketing is realized by installing additional reinforcement and concrete cover around an existing member. It is typically utilized to retrofit elements that are expected to have brittle failure and need an increase in their flexural capacity. It is a popular seismic retrofit method that has been actively researched and applied in the past (e.g. [1-3]) and attracts also more recent scientific interest, with researchers investigating it experimentally [4-9], analytically [10-12] or with the use of structural analysis software [10,13-15]. The focus of recent research efforts appears to be on the better modelling of the interface between the existing element and the concrete jacket, the improvement of analytical methods and the use of new materials.

Steel jacketing is another method used to strengthen individual structural members and increase their deformability and is realized by adding steel jackets around the retrofitted elements. This 
method exploits the nearly full confinement of the existing concrete and the high flexural and shear capacity of the jacket's structural steel to achieve a more ductile behaviour for elements where failure is expected to be brittle $[16,17]$. Its aesthetic effect on the retrofitted building is minimal due to the reduced thickness of the steel jacket compared to reinforced concrete jackets. If the steel jacket is left exposed, it is more susceptible to fire hazard than the reinforced concrete jacket, in which the installed reinforcement is protected by the cover concrete. When the element's flexural capacity does not require to be enhanced, the steel wrapping can be placed only in specific critical areas where plastic hinges are expected to develop. As a variant of this retrofit method, individual steel plates are added to steel and steel-concrete composite beams and steel joints to enhance their capacity. Within the same context, steel plates and beams with I-shaped or U-shaped sections are used to retrofit also reinforced concrete beams $[18,19]$. Full steel jacketing can be analogously applied in practice in the form of interconnected steel strips and angles, forming a steel cage. The application of steel cages is roughly as old as that of reinforced concrete jacketing and is a field of active research efforts as well [20-26].

The second retrofit approach focuses on the overall improvement of a structure as a system, in order to meet the applicable seismic design requirements, therefore this can be characterized as a global approach. New elements are installed to limit the drifts and decrease the ductility demands of the structural system. Such seismic retrofit methods used in structural engineering practice include the integration of new shear walls, steel bracings, base isolators or dampers into an existing structure to achieve the desirable performance. A particularly popular method in practice is the installation of steel bracings in specific bays of the structure. The design of braced frames is nowadays common practice in buildings with steel and steel-concrete composite columns, but they have been used in reinforced concrete structures as well. Research on the utilization of steel bracings as a retrofit method started decades ago and is still active [27-37].

Although the aforementioned methods have been proposed, extensively evaluated and applied for the seismic retrofit of reinforced concrete and steel structures, their effectiveness in the case of steel-concrete composite structures has not yet been thoroughly investigated. Thus, the design and application of retrofit measures for composite structures based on these methods is strongly related to the particular engineer's judgment and experience from applications for other structural systems. In the present work, three methods are evaluated with respect to their cost- 
effectiveness in retrofitting non-code-conforming multi-storey buildings with steel-concrete composite columns. The decision on whether to retrofit a structure or demolish and replace it is predominantly affected by the total cost of the intended retrofit solution. However, the selection of a retrofit solution typically depends on the engineer's subjectivity. Hence, structural optimization [38-42] is employed herein as an objective decision support tool that automatically identifies the best solution on the basis of a 'fair' assessment, as it employs an optimization algorithm to determine the most cost-effective feasible solution according to each retrofit method evaluated. For this purpose, a structural optimization framework presented in [41] is adjusted to the needs of the present work and applied to various cases of 2-, 4- and 6-storey buildings with steel-concrete composite columns in need for seismic retrofit measures.

\section{Retrofit methods}

In this section, the retrofit methods evaluated in the present work are presented and details regarding their implementation in the analysed composite building cases are given.

\subsection{Retrofit of individual elements - Column strengthening}

The local approach of retrofitting individual elements is followed in this work by two methods, which are employed to strengthen steel-concrete composite columns, in order to indirectly improve the buildings' seismic performance: reinforced concrete jacketing and concretecovered steel caging, herein referred to as 'jacket method' and 'cage method', respectively. Both methods have been extensively used in practice to increase the ductility and flexural capacity of deficient or damaged reinforced concrete columns. Their concepts are similar: both are applied by forming a concrete-covered external grid of longitudinal and transversal steel components, which confine the initial and additional concrete of the column, enhancing its ductility and capacity. Additionally, if the longitudinal steel parts are adequately anchored to develop their full capacity, the particular retrofit methods also increase the initial section's stiffness. The main attributes that are different in the two methods are the type of steel elements (bars/strips) comprising the grid that surrounds the initial member, as well as the position/distance of these elements with respect to the centreline of the initial member.

Eurocode 4 [43] specifies that the contribution ratio $\delta$ of structural steel in the resistance of a composite column section to compression should range between 0.2 and 0.9 . This requirement was checked and found to be satisfied for all fully encased steel-concrete composite column 
sections considered in the present study. Clearly, by adding material(s) around the initial sections, their composite behaviour can be significantly altered, shifting the ratio $\delta$ closer to one of the two limit values mentioned above. In the jacket method, the section's extra concrete area added for the retrofit is much larger than the additional steel area of the longitudinal reinforcing bars within the jacket. In the cage method, more structural steel is added for the retrofit to achieve the desirable stiffness, while concrete constitutes only the thin cover layer and the patches between the horizontal and vertical strips; taking also into consideration that the concrete cover is unconfined, the concrete's contribution to the extra capacity of the section is rather low. Hence, with a thick reinforced concrete jacket, the composite section's behaviour resembles more that of a reinforced concrete section (low $\delta$-value), while a steel cage with wide vertical plates increases significantly the contribution of structural steel to the composite section's capacity (high $\delta$-value).

\subsubsection{Reinforced concrete jacketing (jacket method)}

The installation of a reinforced concrete jacket around a column is one of the most commonly used methods in practice to retrofit existing reinforced concrete columns, as well as one of the most intensively investigated in literature. In this method, the extra concrete cover layer added is unconfined, but the rest of the jacket's concrete forms an additional layer of confined concrete core that enhances the column's capacity. Also, the jacket confines the initial element, creating this way a core of super-confined concrete, which increases the column's capacity even further. The jacket method is illustrated in Fig. 1, which shows the locations of the longitudinal bars and the cage formed around the initial composite column. Since failure of the buildings simulated in this investigation was found to be caused mainly by exceedance of the elements' capacity in bending moment, the longitudinal bars of the jacket have a significant effect on the retrofitted section's capacity. Hence, various diameters of bars are considered herein for the longitudinal reinforcement. The effective stiffness added by the jacket is also directly related to the developed capacity of the transversal reinforcement especially at the area of splices, where careful design is needed. In this work, the transversal reinforcement applied is the same for all simulated jacket sizes. The contribution of the added jacket section is analogous to that typically obtained when retrofitting a reinforced concrete column: the longitudinal and transverse reinforcements surrounding the concrete contribute to the section's bending moment and shear capacity, respectively. The longitudinal reinforcement consists of 3 to 5 bars per column side, 
depending on the dimensions of the initial element, while the transverse reinforcement consists of rectangular stirrups that travel around the column (Fig. 1). The same effective concrete cover thickness of $2.5 \mathrm{~cm}$ is applied in all analysed cases.
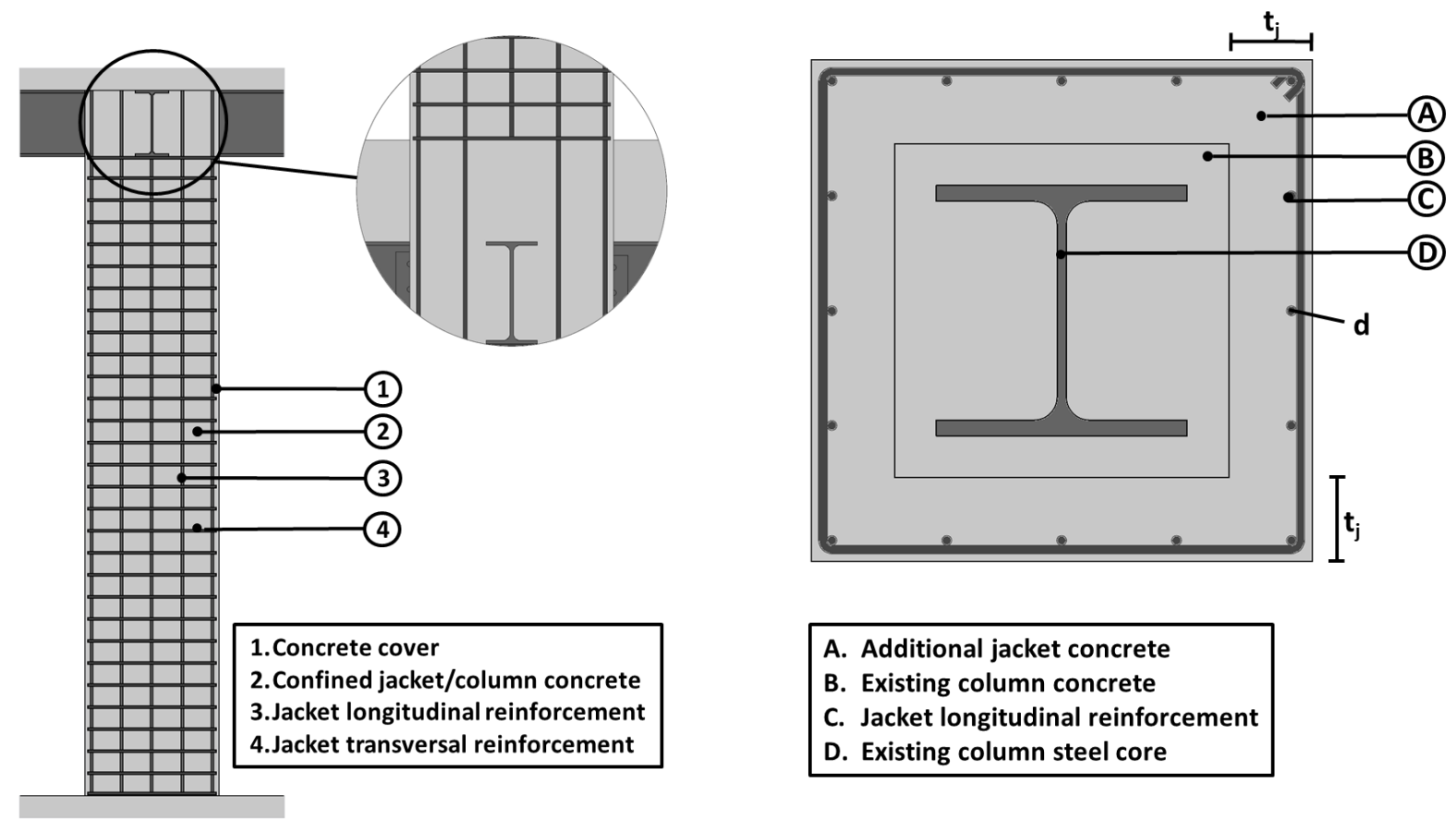
A. Additional jacket concrete
B. Existing column concrete
C. Jacket longitudinal reinforcement
D. Existing column steel core

Fig. 1. Column strengthening using reinforced concrete jacketing (jacket method): side view (left) and crosssection (right) of the retrofitted column.

Since the thickness of the cover concrete, the number of longitudinal bars per column side and the transverse reinforcement in this work are pre-specified for all analyses performed, only 2 parameters are required to define the reinforced concrete jacket applied to a composite column: (a) the total thickness of the jacket per side (denoted as $t_{j}$ in Fig. 1) and (b) the diameter $d$ of the longitudinal bars. In this work, a set of 18 pairs of jacket thicknesses and bar sizes defines the available discrete options, from which a jacket can be selected for retrofitting a column or group of columns. In particular, the first pair provides the option of not retrofitting (no jacket applied). This option allows the optimization algorithm to selectively apply jackets only at specific groups of columns, in order to attain the optimum retrofit design. The second pair is a theoretical option resembling the application of the cage method: the total jacket thickness per column side is set to $7.5 \mathrm{~cm}$ and the bar diameter to $50 \mathrm{~mm}$, thus the jacket bars are placed in direct contact with the existing column, while the additional concrete serves as cover and patches between the bars. Use of this option in an optimized design would be indicative of a preference of the optimizer for retrofit solutions following the cage method. The remaining pairs are 
combinations of various standard bar diameters (up to $32 \mathrm{~mm}$ ) for longitudinal reinforcement with jacket thicknesses of $10 \mathrm{~cm}, 15 \mathrm{~cm}, 20 \mathrm{~cm}$ and $25 \mathrm{~cm}$. It should be noted that large reinforcement bar diameters (>20 mm) are options typically not selected for jackets in practice. Nevertheless, they are made available to the optimizer, because their use in an optimum design is an indicator of need for increase of the corresponding element's stiffness even further than it is actually possible with conventional practices.

\subsubsection{Concrete-covered steel caging (cage method)}

Full steel jacketing is typically applied in deficient or damaged reinforced concrete columns at locations where plastic hinges are expected to develop. The jacket confines the existing concrete, increasing this way the column's ductility and shear capacity and improving its overall performance. When the steel jacket is wide enough, full confinement of the existing concrete can be achieved, producing an effect that is similar to the one observed in concrete-filled tubes, in which the confined concrete can receive stresses significantly higher than its characteristic capacity. However, the main drawback of the steel jacketing technique is the difficulty in installation, as the steel section needs to be placed in at least two separate parts, which are then welded together, in order to surround the existing element. Moreover, when composite action of the jacket and the existing element is also required, additional dowels need to be installed to operate as shear connectors.

The concrete-covered steel cage, which consists of vertical and horizontal plates, can be seen as a hybrid retrofit method, which combines the concrete confinement effect achieved by the installation of steel jackets and the increase of flexural capacity attained by welding longitudinal steel plates on the flanges of I-shaped steel sections. Furtermore, its application in steel-concrete composite columns aims to combine the effectiveness of full steel jaketing with the advantages of the reinforced concrete jacket. In particular, the horizontal plates are mainly intended for increasing the shear capacity and confinement of the concrete, adequately substituting the full steel jacket, while the vertical plates aim mainly at increasing the column's stiffness and flexural capacity. Because the steel plates are placed at larger distances from the composite section's centroid than the steel section's flanges, if the plates are wide enough, the additional flexural capacity achieved may even exceed that of the non-retrofitted section. 
Figure 2 illustrates the cage method as it is implemented in this work. In the vertical direction, the steel cage formed consists of 4 elements of angular section installed at the corners of the steel-concrete composite column and 4 steel plates placed at the middle of each column side. The longitudinal elements are connected with horizontal plates every $20 \mathrm{~cm}$ along the column's height. The whole cage structure can be prepared in two parts, with each part forming an angle that covers 2 of the 4 column sides. Then, the two parts can be placed on the existing column and welded together along two corners. The cover layer of unreinforced concrete applied afterwards has a minimal effect on the total section's capacity and is taken into account as unconfined concrete. Its effective thickness is considered smaller than the typical cover sizes applied.
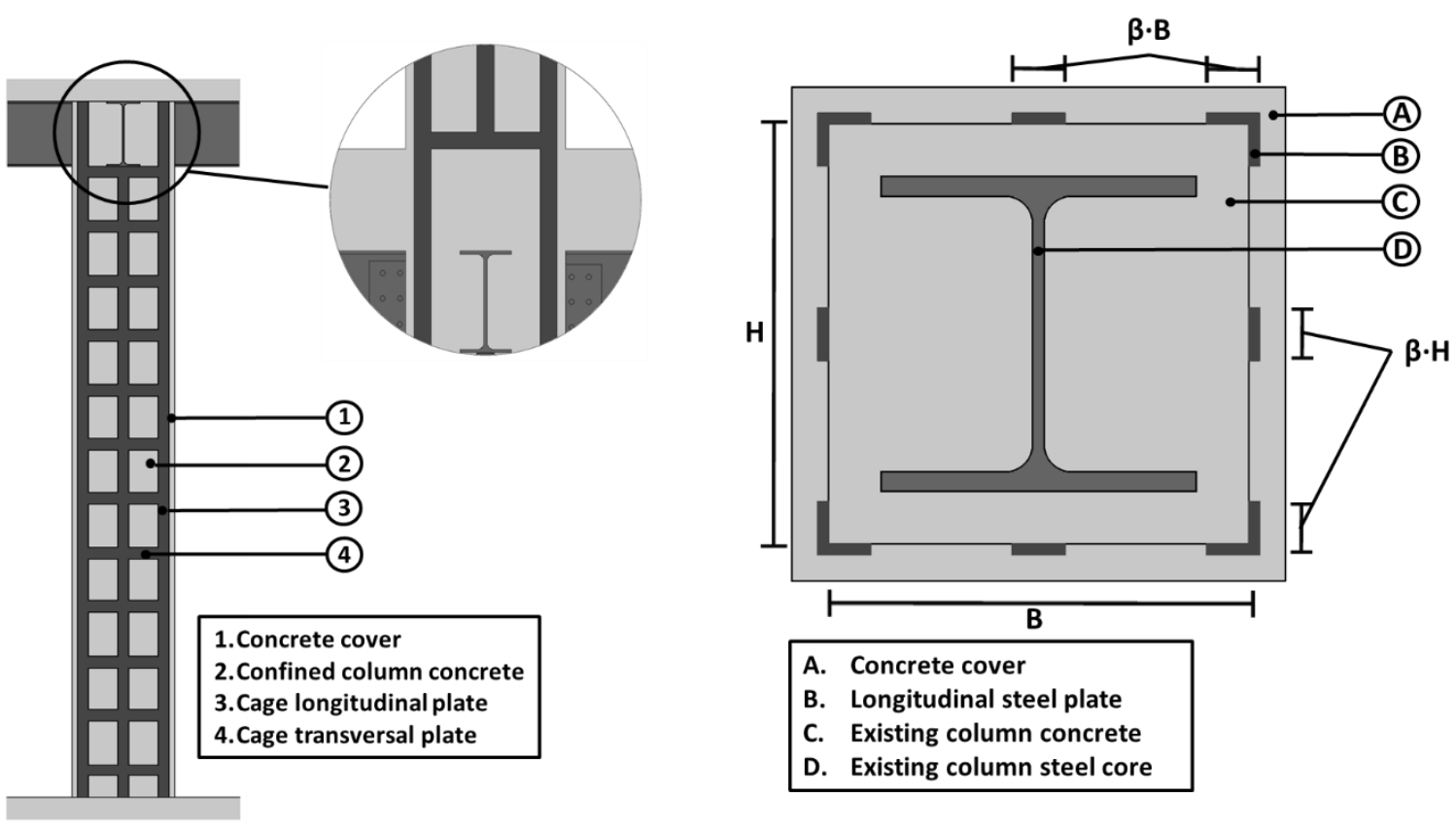

Fig. 2. Column strengthening using concrete-covered steel caging (cage method): side view (left) and crosssection (right) of the retrofitted column.

The plates are placed symmetrically at each opposite side of the composite column. Three longitudinal plates are installed at each column side: 2 at the corners and 1 at the middle (Fig. 2). Their width is denoted as a percentage $\beta$ of the initial section's dimensions: if $H$ is the total side width of the unretrofitted section, then the width of each cage plate installed is $\beta H$ (Fig. 2). A common ratio $\beta$ is applied to all sides of a column, thus, unless the initial column has a square section, the longitudinal plates installed at perpendicular column sides do not have the same width. Taking also into consideration that a fixed concrete cover of $5 \mathrm{~cm}$ around the cage is assumed for all analysis cases, 2 parameters suffice to define the concrete-covered steel cage 
applied to a composite column: (a) the common ratio $\beta$ of the installed longitudinal plates' width over the width of the corresponding column sides and (b) the common thickness $t_{c}$ of all plates installed at the column. In this work, a set of 18 pairs of ratios $\beta$ and thicknesses $t_{c}$ provides the available discrete options, from which a cage can be selected for retrofitting a column or group of columns. The first option to avoid retrofitting specific columns is available in this dataset as well $(\beta=0)$. The second option is a very light retrofit solution $\left(t_{c}=5 \mathrm{~mm}, \beta=5 \%\right)$. The last option corresponds to full steel jacketing of the column $(\beta=33.33 \%$, i.e. the percentage of each column's side covered by the longitudinal steel plates is $3 \beta=100 \%$ ). Plates with thicknesses of $10 \mathrm{~mm}, 15 \mathrm{~mm}, 20 \mathrm{~mm}, 25 \mathrm{~mm}$ and $30 \mathrm{~mm}$ are combined with ratios $\beta$ of $10 \%$, $20 \%$ and $30 \%$ to form the remaining pairs of available options.

\subsection{Overall system retrofit - Adding new members (bracings method)}

There is an upper limit of improvement and cost-effectiveness that can be attained by retrofitting existing elements. Therefore, a second retrofit approach has been developed, according to which the structural upgrade of a non-code-conforming building is achieved by strategically introducing additional members, in order to affect the overall seismic performance of the structural system. Such additional elements could be bracings, shear walls, dampers and base isolators, which receive a large amount of the seismic energy during an earthquake, mitigating this way the damage of the actual building. A common characteristic of the aforementioned extra elements is that, when installed, they all affect significantly the building's fundamental period and, therefore, its behaviour under seismic excitation.

The third retrofit method investigated in the present paper is the installation of steel bracings in predefined bays of the building. When bracings are added to a moment resisting frame, its overall stiffness is significantly increased, while its fundamental period and the consequent ductility demands are reduced. Moreover, due to the steel material's high ductility, the bracings are able to reach large tensile deformations before failure, absorbing, this way, an adequate amount of seismic energy. This retrofit method is particularly suitable for relatively flexible structural systems, such as deficient moment resisting frames. However, it could have an adverse effect in buildings with increased stiffness, as further stiffness increase might result in amplification of the internal forces at the columns, resulting in early failure. 
In this work, the technique used to install bracings at bays of reinforced concrete frames is adopted (Fig. 3). Specifically, in order to make a steel surface available, on which connections can be effectively realized, a portal frame of structural steel is installed at the building's bay considered. This steel frame also protects the beam-column joints from failure due to excessive concentrated load applied by the bracings. The frame consists of members with U-shaped steel sections, with which the existing reinforced concrete columns and beam of the bay are enveloped. These steel members can either have standard UPN sections or custom-made sections; usually the second option is preferred to ensure that the steel sections fit to the shapes of the existing columns and beam. The added steel elements are connected to the existing reinforced concrete members using dowels. Then, connection plates are welded on the webs of the U-shaped elements (or the plates are pre-welded on the webs at the supplier's facilities) and the bracings are bolted to the plates. In buildings with steel-concrete composite columns and steel beams, the top part of the installed steel frame can be defined by the existing steel beam, without adding a new steel member.

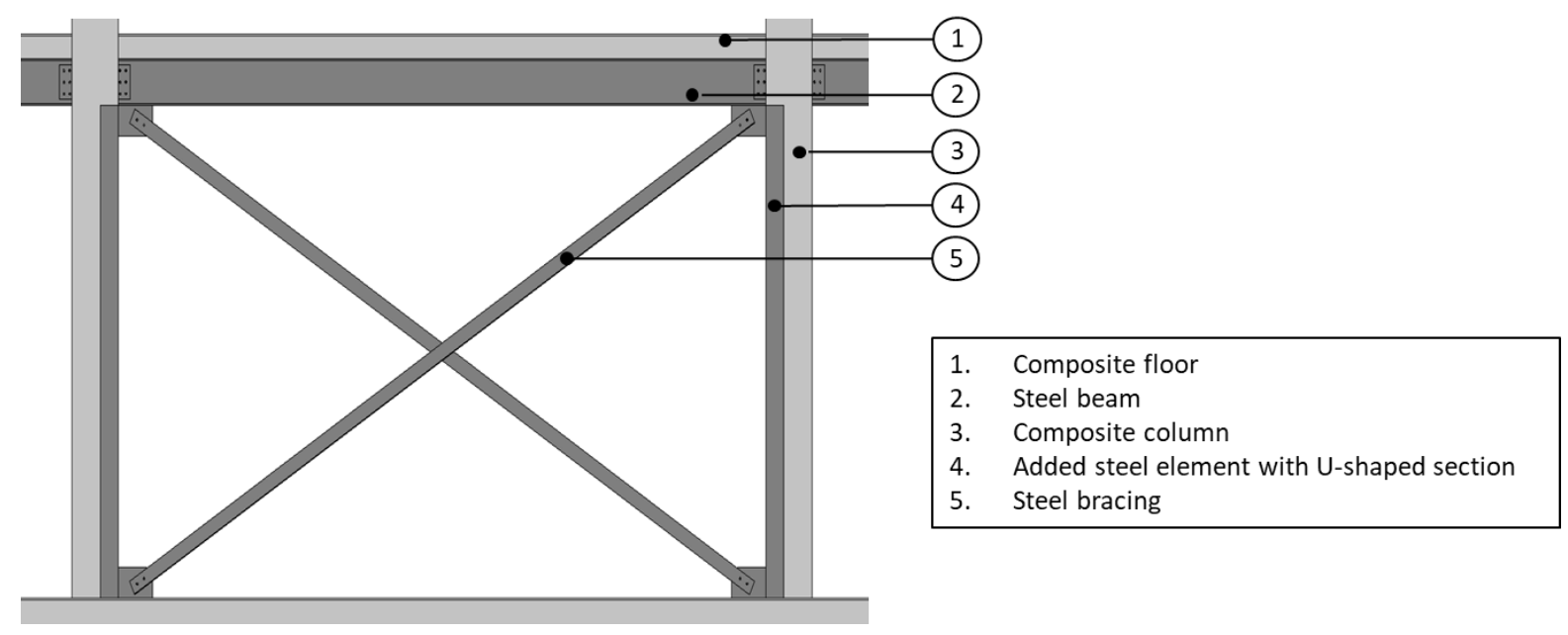

Fig. 3. Structural system upgrade using steel bracing (bracings method): side view of bay with installed bracings.

In total, 17 standard L-shaped sections comprise the set of available options for bracings. Although this type of bracings is susceptible to flexural buckling, L-shaped sections are often preferred in engineering practice for their reduced cost compared to buckling-restrained braces and ease in assembly. In contrast to hollow sections, which require the installation of a cap plate to weld an additional vertical plate to realize the connection, the web of L-sections plays the role of the connection plate. Additionally, when L-sections fail in buckling due to compressive axial force, they develop significant deformations, absorbing this way an amount of the seismic 
energy and preventing the occurrence of further damage at the beam-column joint. Each bracing consists of a pair of L-sections, which can be connected at middle length to reduce the effective length for buckling to half their total length. In the investigation performed herein, such a connection is conservatively not considered. Moreover, because L-sections fail in compression relatively early, the bracings' connections with the frame remain practically undamaged. Even though buckling is generally regarded as an unwanted type of failure, the repair cost of a retrofitted building is significantly reduced, when only the bracings need to be replaced instead of the bracings together with the connection plates due to failure of both components. Special attention needs to be paid to the bottom end of the columns, on which the bracings are installed, due to the large concentrated shear force applied. The steel core of the composite columns of the buildings simulated in this work was found to suffice, in order to receive the full amount of shear force. The same does not apply for analogous applications in reinforced concrete structures, where the shear force needs to be received almost entirely by stirrups (or diagonal reinforcement), therefore it is a potential location where shear failure might occur. Note that the database with L-shaped sections additionally includes a 'zero' option (no bracing section), which actually offers the optimizer the choice to deactivate bracings.

\section{Structural Modelling and Analyses}

All structural simulations are performed using OpenSEES [44]. The particular structural analysis software provides the capability of handling various material types in a single member section and, therefore, can simulate effectively the composite columns without and with retrofit measures installed. Hence, the existing steel beams and the steel core of the composite columns, as well as the installed bracings and the steel components of the concrete-covered steel cage are assumed to consist of the same quality of structural steel S235 and simulated using the bilinear material model 'Steel01'. Particular attention is paid so that the final retrofitted building designs do not exceed the ultimate strain of steel or the critical stress for buckling, as otherwise overestimated element capacity would be considered. The 'Concrete 01 ' material model is employed for the simulation of all concrete regions in a building, i.e. of both the existing composite columns' concrete and that of the retrofit sections. This model is implemented with no tensile capacity, while its compressive strength is taken as $20 \mathrm{MPa}$ and the cracking and crashing strains as $2 \%$ and $3.5 \%$, respectively. The longitudinal and transverse reinforcement bars of the existing composite columns and of the reinforced concrete jacket are modelled using 
the 'ReinforcingSteel' material type. This model differs from 'Steel01' in its post-yield branch, as it consists of a horizontal plateau and a hardening-softening part. Its yield stress is taken as $500 \mathrm{MPa}$ and its ultimate strain as $20 \%$.

The non-retrofitted and retrofitted columns, the beams and the bracings are simulated using distributed plasticity (fiber section) elements of OpenSEES. In particular, columns and beams are modelled as 'nonlinearBeamColumn' elements in the $x$-direction (i.e. parallel to the major axes of all columns' HEB steel cores) and 'beamWithHinges' in the $y$-direction, while 'truss' elements are used for bracings [44]. The composite slabs are considered to perform as rigid diaphragms at the horizontal plane. The stiffness required for the diaphragm behaviour of the floor in the direction that is orthogonal to the corrugations is provided by secondary beams. The slabs' effect on the structural performance is taken into account by defining a 'rigidDiaphragm' [44] for each storey, while their loads are transferred as distributed loads on the beams. All beam-column connections are considered to be able to fully transfer the loads and moments they receive in the global $x$-direction and operate as simple supports in the global $y$-direction. Column base connections are modelled as fixed supports. It is also worth mentioning the assumption made that, in the analysed structural models, an effective connection between the elevator/staircase reinforced concrete core wall that might be present in the 4-storey and 6storey buildings and the lateral resisting system is not implemented, i.e. the core is detached from the lateral resisting system. In the case of an effective connection, the contribution of the core to the overall building stiffness could be significant with a consequent substantial effect on the retrofit optimization results, depending also on the core's position within the building's floor plan.

Three types of structural analyses are performed in this work using OpenSEES for any candidate optimum structural design assessed. Initially, a linear static analysis under gravitational loads takes place, in order to apply the gravitational loads on the structural model, as well as to obtain analysis results needed for the initial capacity checks of structural elements. Once the gravitational loads are applied and the total mass of each storey is defined, two eigenvalue analyses are performed (one for each horizontal direction $x$ and $y$ ), in order to determine the maximum fundamental period of the building and define parameters required for the next analyses. Finally, two nonlinear static analyses under horizontal loads (pushover 
analyses) are performed (one for each horizontal direction $x$ and $y$ ) up to a targeted top displacement, in order to assess the seismic performance of the building under evaluation.

\section{Structural Optimization}

The Evolution Strategies (ES) [45] optimization algorithm is utilized for the computational investigation performed in the present work. The particular algorithm, which imitates the evolution of a species in time, is a well-established derivative-free optimization method particularly suitable for engineering problems. The optimization procedure employed herein is an adjusted version of the one developed in [41]. In this section, a description is provided for this adjusted implementation, which is tailored to the needs of the optimization problems dealt with in the next section.

\subsection{Design variables}

The basic idea in each case study of the present paper is to initially consider an existing, possibly under-designed moment-resisting frame with specific steel-concrete composite columns and steel beams. Hence, the initial design of the studied building is fixed and the purpose of the optimization procedure is to determine (if needed) an optimal retrofit solution using the approaches presented in section 2. In the sequel of this work, the term 'design' is used to refer to a retrofit solution.

The design variables are the parameters, the values of which are altered during the search for the optimum solution. In this paper, the design variables fully control the retrofit solution of a candidate optimum design as described in section 2. Specifically, for the jacket method and for each column-group defined, a design variable is specified to control the jacket's concrete thickness and reinforcing bar size; for the cage method and for each column-group defined, a design variable is specified to control the width and thickness of the steel plates installed at column sides; for the bracings method, two design variables are specified to control the Lshaped sections of bracings installed along directions $x$ and $y$ of the building.

The optimization problems handled in the present study are of discrete type: the search space of candidate optimum solutions is defined through the options for design variable values, which are not taken from a continuous range, but from a set of specific (discrete) available sizes of retrofit components (the options for design variable values are defined in section 2). In 
engineering practice, standardization of dimensions and formation of respective discrete databases of available options is essential, as production of structural components with a limited number of sizes can speed up construction and reduce costs. Optimization runs using a continuous search space would yield retrofit solutions with impractical, non-standard section dimensions. Therefore, for any candidate optimum solution considered herein, each design variable actually takes an integer value (identification number), which corresponds to a particular discrete option provided in the respective database.

\subsection{Objective function}

The objective of the optimization process is to minimize the total cost of structural materials required to retrofit the building under consideration. The cost of materials for existing elements of the building in its initial (non-retrofitted) state are not taken into account in the employed objective function. Hence, the total cost of structural materials added to retrofit the building can be calculated as the sum of the costs of extra steel and concrete installed when any of the 3 retrofit approaches of section 2 is applied. Nevertheless, the calculation of the materials costs in monetary units implies that a 'subjective' final optimization result will be obtained that will depend on the average material prices, which vary at different locations and typically fluctuate with time, i.e. the optimality of a design identified by the optimization procedure will always be linked with a specific location and a certain period of time.

A way to improve the 'objectivity' of the utilized optimization procedure is to employ the Cost Ratio $C R$ introduced in [41]. This is defined as $C R=C_{c} / C_{s}$, where $C_{s}$ and $C_{c}$ are average total unit costs for steel and concrete, respectively. As the cost of concrete is typically calculated based on its volume and that of steel based on its mass, the unit costs $C_{s}$ and $C_{c}$ can be specified in $€ /$ tn and $€ / \mathrm{m}^{3}$, respectively, thus $C R$ is given in $\mathrm{tn} / \mathrm{m}^{3}$. The cost ratio may also vary with time and location, however other factors, such as a general increase in prices due to inflation or fluctuation in currency exchange rates, are expected to have a small or even no effect on the value of $C R$. Hence, the cost ratio $C R$ seems to be a more robust choice to link the costs of steel and concrete in an objective function, rather than explicitly using the unit costs $C_{s}$ and $C_{c}$. In this work, a cost ratio of $1.2 \%\left(\mathrm{tn} / \mathrm{m}^{3}\right)$ is adopted for all optimization runs performed, which indicates the availability of 'cheap' concrete and 'expensive' steel, as is typically the case in Cyprus. 
Following the definition of the cost ratio $C R$, the objective function employed in the optimization procedure measures the total equivalent steel mass of retrofit materials $M_{s}^{\text {tot }}$ (tn of steel) in the structure and can be written as:

$M_{s}^{t o t}=M_{S}+C R \cdot V_{C}$,

where $M_{S}$ and $V_{C}$ are the total steel mass (tn) and concrete volume $\left(\mathrm{m}^{3}\right)$, respectively, of retrofit materials used in the structure. Hence, the objective function is expressed as the sum of the actual steel mass and the converted concrete mass of installed materials to retrofit the building under consideration.

\subsection{Constraints}

In a structural optimization problem, constraint functions are evaluated using the results of structural analyses for each candidate optimum design, in order to assess the overall performance of the building, as well as of its individual structural components, with respect to predefined criteria. The constraints imposed in the framework of the optimization procedure in this work are:

(a) The retrofitted structure for any candidate optimum design is required to satisfy the capacity criteria defined in Eurocode 3 [46] for pure steel members and Eurocode 4 [43] for steel-concrete composite members. The provisions of Eurocode 4 regarding the capacity in axial force, shear force, bending moment, combined axial force and biaxial bending moment and the respective types of local and global buckling are evaluated to check the composite columns. The pure steel beams are checked for their capacity in shear force, bending moment and their interaction, as well as the respective types of local and global buckling according to the provisions of Eurocode 3. The aforementioned checks are performed based on the results of the initial linear static analysis of the structure. Note that, although bracings are pure steel members, they are not checked with respect to the provisions of Eurocode 3. The bracings' contribution to the load transferring mechanism of the structure is actually activated under seismic action, therefore bracing sections are determined based on the global structural system performance and not on local member/section capacity criteria.

(b) The overall structural performance of the retrofitted structure under horizontal loading is assessed in accordance with provisions of ASCE/SEI 41-06 [47]. In particular, two 
displacement-controlled pushover analyses (in horizontal directions $x$ and $y$ ) up to the targeted top displacement specified in FEMA-440 [48] are performed for each candidate optimum design. The maximum interstorey drift is used as an overall structural performance indicator. Its maximum value is retrieved from Table C1-3 of ASCE/SEI 4106 [47] for the collapse prevention limit state. The limit values provided therein are $4 \%$ of the storey height for reinforced concrete frames and 5\% for steel frames. As there is no provision for steel-concrete composite frames, the $4 \%$ limit for reinforced concrete frames is selected herein as a conservative requirement.

(c) A limit on the maximum fundamental period of the retrofitted building is imposed using the formula of Goel and Chopra [49] for steel moment-resisting frames (again, there is no respective information specifically for steel-concrete composite frames).

All aforementioned constraints need to be satisfied by any candidate optimum design to be considered feasible. Violation of at least one requirement renders the assessed design infeasible and the optimization algorithm adds a penalty to the objective function value. Specifically, the total equivalent steel mass for retrofit materials of an infeasible design is increased by the respective mass of a building with the same geometrical characteristics, which is retrofitted with the largest available sections in the utilized databases, rounded up to 50 tons. It should be noted that, while the local member/section capacity checks of Eurocodes 3 and 4 are used as feasibility criteria using the linear static analysis results, the same does not apply to the performance of structural components under seismic action. Hence, individual components are allowed to fail during both pushover analyses performed, provided that such local failures do not trigger partial or full collapse of the analysed building.

\section{Optimization Results}

In this section, the cost-effectiveness of the retrofit methods described in section 2 is assessed using the presented optimization procedure. For this purpose, three buildings are assessed, which have the same 5-by-5-bay symmetric floor plan, but a different number of storeys: a 2storey, a 4-storey and a 6-storey building. The 6-storey structure is illustrated in Fig. 4. For all three buildings, the span of each beam is $6 \mathrm{~m}$, calculated as the distance between the centroids of the two columns, to which the beam is attached. As regards columns, all have a height of $3.5 \mathrm{~m}$ and are considered to have the same orientation, with their HEB steel cores' major axes 
being parallel to the global $x$-direction. Hence, a global 'major axis' and a global 'minor axis' (parallel to the global $x$ - and $y$-directions, respectively) are defined for each storey, as well as for the whole building as a system.

The first step of the assessment procedure followed herein is to design the three structures in a way that all requirements outlined in subsection 4.3 are satisfied using the smallest possible member sizes (reference buildings). A single size of HEB steel core is used for all composite columns of each building. In preliminary analyses it was noticed that the beam sections required for the gravitational loads generally suffice when the buildings are evaluated for horizontal loads. Hence, it remains to identify the columns' smallest possible HEB size for each reference building, which renders the design of the 3 code-conforming buildings a simple trial-and-error procedure: starting from a small HEB steel core size, it is increased one standard size at a time until a design is determined that satisfies all criteria of subsection 4.3. Thus, composite columns with HE550B steel cores are required for the 2-storey reference building and HE800B for the 4-storey reference building, both designed as Moment-Resisting Frames (MRFs). For the 6storey building, the largest available column section does not suffice, therefore it is designed as a braced frame: the minimum bracing size is used at the corner bays (as indicated in Fig. 4) and the above mentioned trial-and-error procedure is followed. The design identified for the 6storey reference building with this procedure has composite columns with HE320B steel cores and L90 $\times 90 \times 7$ steel bracings at the corner bays.

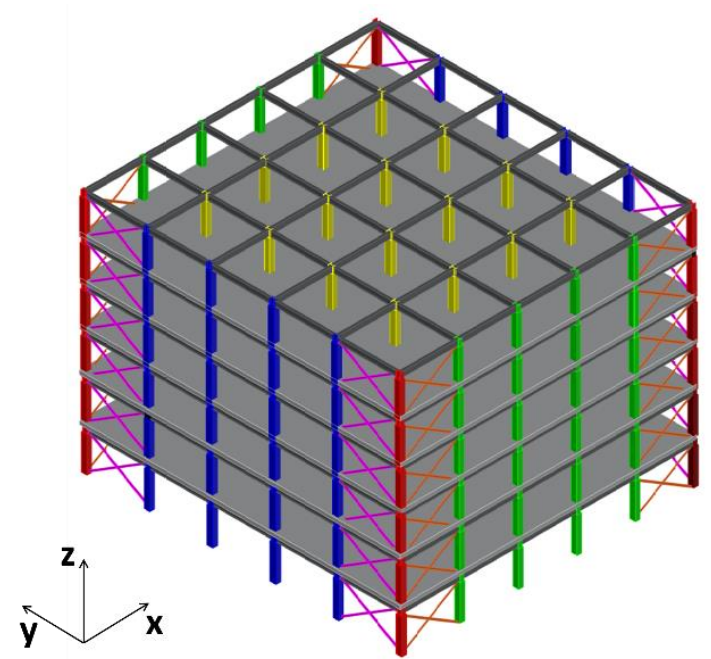

Group 1 (Corner Columns)

Group 2 (Peripheral Columns in x-direction)

Group 3 (Peripheral Columns in y-direction)

Group 4 (Internal Columns)

Group 5 (Bracings in $\mathrm{x}$-direction)

Group 6 (Bracings in y-direction)

Fig. 4. Member groups illustrated on the 6-storey building (top slab removed for visualization purposes). 
Using smaller steel core sizes for the composite columns than the ones determined for each reference building above, a total number of 30 under-designed buildings are generated. More specifically, sections down to HE180B are used for the 2-storey MRF (13 cases of deficient buildings), sections down to HE280B for the 4-storey MRF (12 cases) and sections from HE220B to HE300B for the 6-storey braced frame (5 cases). Note that, as in the case of the 6storey reference building, all under-designed and unretrofitted 6-storey buildings have the minimum L90 $\times 90 \times 7$ steel bracings installed at the corner bays. In all 30 under-designed cases, the buildings are retrofitted using each of the three methods described in section 2 in the framework of the utilized optimization procedure. To facilitate the optimization process, columns are organized into 4 groups according to their location in the floor plan (column groups 1-4 in Fig. 4): (1) corner, (2) peripheral at the sides parallel to global $x$-direction, (3) peripheral at the sides parallel to global $y$-direction and (4) internal. Hence, the columns of each group have a constant size along the height of the building. Two additional groups are defined for the bracings (bracings groups 5, 6 in Fig. 4): (5) at the corner bays of the sides parallel to global $x$ direction and (6) at the corner bays of the sides parallel to global $y$-direction. One discrete design variable controls the retrofit choice for each of these 6 member-groups. As already mentioned in section 2, 'zero' options are included in all utilized databases and are available to be chosen as design variable values. This allows the optimization procedure, in its effort to identify the most cost-effective retrofit solution, to activate or deactivate the 2 column strengthening approaches (jacket and cage methods) for any of the 4 column-groups and the bracings along any of directions $x$ and $y$.

Four different retrofit optimization runs are performed for each of the under-designed buildings defined. In each of the first two optimization runs, only one of the column-strengthening methods is enabled: the jacket method is applied in the first run and the cage method in the second run. For the remaining two optimization runs, the bracings method is enabled in combination each time with one of the two aforementioned column strengthening methods. In the case of the 6-storey braced frame, the bracings chosen to retrofit the building are assumed to replace the ones initially installed (if different). A total number of 120 retrofit optimization runs were performed, the results of which are presented in Tables 1, 2 and 3 for the 2-storey, 4storey and 6-storey buildings, respectively. 
A macroscopic conclusion drawn from the results of these tables is that the optimal retrofit approach is decisively affected by: (a) how much under-designed a building is compared to the corresponding feasible non-retrofitted building designed initially and (b) the type of structural system of the building (MRF or braced frame). These factors are related to the fundamental period of the building that seems to play an important role in the process of identifying a costeffective retrofit solution. Indeed, certain building designs exhibited maximum interstorey drifts that were considerably less than the imposed limit of $4 \%$ of the storey height, however they also had rather high fundamental periods that rendered them unacceptable. As a result of increasing the structural system's stiffness to address the high fundamental period problem, the maximum recorded interstorey drifts were further reduced (actually, they do not exceed the value of $2.2 \%$ of the storey height for all optimized retrofit solutions in this paper). Hence, a designer could use the eigenvalue analysis results to have a strong indication of design feasibility or infeasibility and avoid the need to also perform pushover analyses for designs that would be proven infeasible after all. Clearly, for a retrofit solution with acceptable fundamental period, subsequent pushover analysis results are required to formally check interstorey drifts.

Table 1. Optimized retrofit solutions for under-designed 2-storey buildings.

\section{REINFORCED CONCRETE JACKETS}

\begin{tabular}{clllll}
\hline $\begin{array}{l}\text { Column sections } \\
\text { (steel core) }\end{array}$ & Column group 1 & Column group 2 & Column group 3 & Column group 4 & $\begin{array}{l}\text { Total retrofit demand } \\
\text { (equivalent kg steel) }\end{array}$ \\
\hline HE180B & $d=12 \mathrm{~mm}, t_{j}=25 \mathrm{~cm}$ & $d=12 \mathrm{~mm}, t_{j}=15 \mathrm{~cm}$ & Not required & $d=12 \mathrm{~mm}, t_{j}=20 \mathrm{~cm}$ & 11,460 \\
HE200B & Not required & Not required & Not required & $d=12 \mathrm{~mm}, t_{j}=25 \mathrm{~cm}$ & 8,983 \\
HE220B & Not required & Not required & Not required & $d=12 \mathrm{~mm}, t_{j}=25 \mathrm{~cm}$ & 9,252 \\
HE240B & Not required & Not required & Not required & $d=12 \mathrm{~mm}, t_{j}=25 \mathrm{~cm}$ & 9,521 \\
HE260B & Not required & Not required & Not required & $d=12 \mathrm{~mm}, t_{j}=20 \mathrm{~cm}$ & 7,612 \\
HE280B & Not required & Not required & Not required & $d=12 \mathrm{~mm}, t_{j}=20 \mathrm{~cm}$ & 7,827 \\
HE300B & $d=12 \mathrm{~mm}, t_{j}=10 \mathrm{~cm}$ Not required & Not required & $d=12 \mathrm{~mm}, t_{j}=15 \mathrm{~cm}$ & 7,096 \\
HE320B & Not required & Not required & Not required & $d=12 \mathrm{~mm}, t_{j}=15 \mathrm{~cm}$ & 6,107 \\
HE340B & Not required & Not required & Not required & $d=12 \mathrm{~mm}, t_{j}=15 \mathrm{~cm}$ & 6,187 \\
HE360B & Not required & Not required & $d=12 \mathrm{~mm}, t_{j}=20 \mathrm{~cm}$ & Not required & 4,182 \\
HE400B & Not required & Not required & $d=12 \mathrm{~mm}, t_{j}=15 \mathrm{~cm}$ & Not required & 3,215 \\
HE450B & Not required & Not required & $d=12 \mathrm{~mm}, t_{j}=10 \mathrm{~cm}$ & Not required & 2,341 \\
HE500B & $d=12 \mathrm{~mm}, t_{j}=10 \mathrm{~cm}$ & Not required & Not required & Not required & 1,204 \\
$\geq$ HE550B & - & - & - & - & Not required \\
\hline
\end{tabular}

\section{CONCRETE-COVERED STEEL CAGES}

\begin{tabular}{|c|c|c|c|c|c|}
\hline $\begin{array}{l}\text { Column sections } \\
\text { (steel core) }\end{array}$ & Column group 1 & Column group 2 & Column group 3 & Column group 4 & $\begin{array}{l}\text { Total retrofit demand } \\
\text { (equivalent kg steel) }\end{array}$ \\
\hline HE180B-HE360B & - & - & - & - & Infeasible \\
\hline HE400B & $t_{c}=20 \mathrm{~mm}, \beta=10 \%$ & $t_{c}=40 \mathrm{~mm}, \beta=33,3 \%$ & $t_{c}=40 \mathrm{~mm}, \beta=33,3 \%$ & $t_{c}=40 \mathrm{~mm}, \beta=33,3 \%$ & 106,946 \\
\hline HE450B & Not required & Not required & Not required & $t_{c}=25 \mathrm{~mm}, \beta=10 \%$ & 11,003 \\
\hline HE500B & Not required & Not required & Not required & $t_{c}=10 \mathrm{~mm}, \beta=10 \%$ & 5,198 \\
\hline$\geq$ HE550B & - & - & - & - & Not required \\
\hline \multicolumn{6}{|c|}{ STEEL BRACINGS } \\
\hline $\begin{array}{l}\text { Column sections } \\
\text { (steel core) }\end{array}$ & Bracings group 5 & & Bracings group 6 & & $\begin{array}{l}\text { Total retrofit demand } \\
\text { (equivalent kg steel) }\end{array}$ \\
\hline
\end{tabular}




\begin{tabular}{clll} 
HE180B-HE500B L $90 \times 90 \times 7$ & L $90 \times 90 \times 7$ & $3,039-3,756$ \\
$\geq$ HE550B & - & - & Not required \\
\hline
\end{tabular}

Table 2. Optimized retrofit solutions for under-designed 4-storey buildings.

\section{REINFORCED CONCRETE JACKETS}

\begin{tabular}{|c|c|c|c|c|c|}
\hline $\begin{array}{l}\text { Column sections } \\
\text { (steel core) }\end{array}$ & Column group 1 & Column group 2 & Column group 3 & Column group 4 & $\begin{array}{l}\text { Total retrofit demand } \\
\text { (equivalent kg steel) }\end{array}$ \\
\hline HE280B & $d=12 \mathrm{~mm}, t_{j}=25 \mathrm{~cm}$ & $d=12 \mathrm{~mm}, t_{j}=25 \mathrm{~cm}$ & $d=20 \mathrm{~mm}, t_{j}=25 \mathrm{~cm}$ & $d=12 \mathrm{~mm}, t_{j}=25 \mathrm{~cm}$ & 48,090 \\
\hline HE300B & $d=25 \mathrm{~mm}, t_{j}=25 \mathrm{~cm}$ & $d=12 \mathrm{~mm}, t_{j}=25 \mathrm{~cm}$ & $d=12 \mathrm{~mm}, t_{j}=20 \mathrm{~cm}$ & $d=12 \mathrm{~mm}, t_{j}=25 \mathrm{~cm}$ & 46,844 \\
\hline HE320B & $d=12 \mathrm{~mm}, t_{j}=10 \mathrm{~cm}$ & $d=12 \mathrm{~mm}, t_{j}=20 \mathrm{~cm}$ & $d=12 \mathrm{~mm}, t_{j}=25 \mathrm{~cm}$ & $d=12 \mathrm{~mm}, t_{j}=25 \mathrm{~cm}$ & 41,700 \\
\hline HE340B & $d=12 \mathrm{~mm}, t_{j}=10 \mathrm{~cm}$ & Not required & $d=12 \mathrm{~mm}, t_{j}=25 \mathrm{~cm}$ & $d=12 \mathrm{~mm}, t_{j}=25 \mathrm{~cm}$ & 33,981 \\
\hline HE360B & Not required & Not required & $d=12 \mathrm{~mm}, t_{j}=25 \mathrm{~cm}$ & $d=12 \mathrm{~mm}, t_{j}=25 \mathrm{~cm}$ & 32,190 \\
\hline HE400B & $d=12 \mathrm{~mm}, t_{j}=20 \mathrm{~cm}$ & Not required & Not required & $d=12 \mathrm{~mm}, t_{j}=25 \mathrm{~cm}$ & 26,288 \\
\hline HE450B & $d=12 \mathrm{~mm}, t_{j}=15 \mathrm{~cm}$ & $d=12 \mathrm{~mm}, t_{j}=10 \mathrm{~cm}$ & Not required & $d=12 \mathrm{~mm}, t_{j}=20 \mathrm{~cm}$ & 25,695 \\
\hline HE500B & Not required & Not required & $d=20 \mathrm{~mm}, t_{j}=15 \mathrm{~cm}$ & $d=12 \mathrm{~mm}, t_{j}=15 \mathrm{~cm}$ & 23,326 \\
\hline HE550B & $d=25 \mathrm{~mm}, t_{j}=25 \mathrm{~cm}$ & Not required & Not required & $d=12 \mathrm{~mm}, t_{j}=10 \mathrm{~cm}$ & 18,563 \\
\hline HE600B & $d=12 \mathrm{~mm}, t_{j}=10 \mathrm{~cm}$ & Not required & Not required & $d=12 \mathrm{~mm}, t_{j}=10 \mathrm{~cm}$ & 12,713 \\
\hline HE650B & Not required & Not required & $d=25 \mathrm{~mm}, t_{j}=10 \mathrm{~cm}$ & Not required & 10,534 \\
\hline HE700B & Not required & Not required & $d=12 \mathrm{~mm}, t_{j}=10 \mathrm{~cm}$ & Not required & 5,354 \\
\hline$\geq$ HE800B & - & - & - & - & Not required \\
\hline \multicolumn{6}{|c|}{ CONCRETE-COVERED STEEL CAGES } \\
\hline $\begin{array}{l}\text { Column sections } \\
\text { (steel core) }\end{array}$ & Column group 1 & Column group 2 & Column group 3 & Column group 4 & $\begin{array}{l}\text { Total retrofit demand } \\
\text { (equivalent kg steel) }\end{array}$ \\
\hline HE280B-HE600B & & - & - & - & Infeasible \\
\hline HE650B & $t_{c}=10 \mathrm{~mm}, \beta=10 \%$ & $t_{c}=40 \mathrm{~mm}, \beta=33,3 \%$ & $t_{c}=40 \mathrm{~mm}, \beta=33,3 \%$ & $t_{c}=40 \mathrm{~mm}, \beta=33,3 \%$ & 276,988 \\
\hline HE700B & Not required & Not required & Not required & $t_{c}=20 \mathrm{~mm}, \beta=10 \%$ & 23,841 \\
\hline$\geq$ HE800B & - & - & - & - & Not required \\
\hline \multicolumn{6}{|c|}{ STEEL BRACINGS } \\
\hline $\begin{array}{l}\text { Column sections } \\
\text { (steel core) }\end{array}$ & Bracings group 5 & & Bracings group 6 & & $\begin{array}{l}\text { Total retrofit demand } \\
\text { (equivalent kg steel) }\end{array}$ \\
\hline HE280B-HE700B & L $90 \times 90 \times 7$ & & L $90 \times 90 \times 7$ & & $6,730-8,164$ \\
\hline$\geq$ HE800B & - & & - & & Not required \\
\hline
\end{tabular}

Table 3. Optimized retrofit solutions for under-designed 6-storey buildings.

\section{REINFORCED CONCRETE JACKETS}

\begin{tabular}{clllll}
\hline $\begin{array}{l}\text { Column sections } \\
\text { (steel core) }\end{array}$ & Column group 1 & Column group 2 & Column group 3 & Column group 4 & $\begin{array}{l}\text { Total retrofit demand } \\
\text { (equivalent kg steel) }\end{array}$ \\
\hline HE220B & $d=20 \mathrm{~mm}, t_{j}=10 \mathrm{~cm}$ & Not required & $d=12 \mathrm{~mm}, t_{j}=10 \mathrm{~cm}$ & $d=12 \mathrm{~mm}, t_{j}=10 \mathrm{~cm}$ & 22,328 \\
HE240B & $d=12 \mathrm{~mm}, t_{j}=10 \mathrm{~cm}$ & Not required & $d=12 \mathrm{~mm}, t_{j}=10 \mathrm{~cm}$ & $d=12 \mathrm{~mm}, t_{j}=10 \mathrm{~cm}$ & 20,771 \\
HE260B & Not required & Not required & Not required & $d=12 \mathrm{~mm}, t_{j}=10 \mathrm{~cm}$ & 12,192 \\
HE280B & Not required & Not required & $d=12 \mathrm{~mm}, t_{j}=10 \mathrm{~cm}$ & Not required & 6,257 \\
HE300B & $d=12 \mathrm{~mm}, t_{j}=10 \mathrm{~cm}$ & Not required & Not required & Not required & 3,209 \\
$\geq$ HE320B & - & - & - & - & Not required \\
\hline
\end{tabular}

\section{CONCRETE-COVERED STEEL CAGES}

\begin{tabular}{|c|c|c|c|c|c|}
\hline $\begin{array}{l}\text { Column sections } \\
\text { (steel core) }\end{array}$ & Column group 1 & Column group 2 & Column group 3 & Column group 4 & $\begin{array}{l}\text { Total retrofit demand } \\
\text { (equivalent kg steel) }\end{array}$ \\
\hline HE220B & - & - & - & - & Infeasible \\
\hline HE240B & $t_{c}=25 \mathrm{~mm}, \beta=10 \%$ & $t_{c}=5 \mathrm{~mm}, \beta=5 \%$ & $t_{c}=30 \mathrm{~mm}, \beta=10 \%$ & $t_{c}=25 \mathrm{~mm}, \beta=10 \%$ & 40,868 \\
\hline HE260B & $t_{c}=10 \mathrm{~mm}, \beta=10 \%$ & $t_{c}=15 \mathrm{~mm}, \beta=10 \%$ & $t_{c}=15 \mathrm{~mm}, \beta=10 \%$ & $t_{c}=5 \mathrm{~mm}, \beta=5 \%$ & 21,238 \\
\hline HE280B & $t_{c}=5 \mathrm{~mm}, \beta=5 \%$ & Not required & $t_{c}=5 \mathrm{~mm}, \beta=5 \%$ & $t_{c}=5 \mathrm{~mm}, \beta=5 \%$ & 5,344 \\
\hline HE300B & Not required & Not required & $t_{c}=5 \mathrm{~mm}, \beta=5 \%$ & Not required & 1,614 \\
\hline$\geq$ HE320B & - & - & - & - & Not required \\
\hline \multicolumn{6}{|c|}{ STEEL BRACINGS } \\
\hline $\begin{array}{l}\text { Column sections } \\
\text { (steel core) }\end{array}$ & Bracings group 5 & \multicolumn{3}{|c|}{ Ip 6} & $\begin{array}{l}\text { Total retrofit demand } \\
\text { (equivalent kg steel) }\end{array}$ \\
\hline \multicolumn{3}{|c|}{ HE220B-HE240B - } & \multirow{3}{*}{\multicolumn{2}{|c|}{ L $120 \times 80 \times 8$}} & Infeasible \\
\hline \multicolumn{3}{|c|}{$\begin{array}{l}\text { HE260B-HE300B L } 120 \times 80 \times 8 \\
>\text { HE }\end{array}$} & & & $11,524-11,907$ \\
\hline$\geq$ HE320B & \multicolumn{2}{|l|}{-} & & & Not required \\
\hline
\end{tabular}


In the remainder of this section, specific remarks are made on the effectiveness of each the 3 retrofit approaches assessed based on the obtained optimization results.

\subsection{Cage Method}

The cage method is the least invasive of the retrofit approaches assessed in the present work, as its application results only in a small increase of the section areas of the retrofitted columns. Therefore, the method's effectiveness in increasing the capacity of columns is limited. Hence, the results obtained herein show that this method is really effective in increasing the columns' capacity and stiffness and improving a building's overall performance when only limited strengthening is required. However, for a well under-designed building with rather weak columns, there is an abrupt increase in the total retrofit cost, because the distances of the installed steel cages from the columns' centroids are fixed, unlike in the case of reinforced concrete jackets, in which jacket thicknesses can be increased to move steel reinforcing bars away from the columns' centroids.

Indeed, as regards the MRFs of the 2-storey and 4-storey buildings, it can be seen in Tables 1 and 2 that feasible retrofit solutions can be determined using the cage method for a rather limited number of cases, in which deficient columns are only a little weaker than the ones of the corresponding code-conforming reference buildings. For under-designed buildings with even weaker columns than the ones successfully retrofitted, no feasible retrofit solutions can be identified using the cage method. Notice that, in the weakest of the retrofitted 2-storey and 4storey buildings, the total retrofit cost is so high that it renders the cage method practically unacceptable, even if architectural constraints discourage the application of an alternative, more invasive retrofit method. Hence, the cage method appears to be inefficient in retrofitting the 2storey and 4-storey MRFs, as it struggles to find costly column caging designs with wide and thick steel plates (as indicated by the values of $t_{c}$ and $\beta$ in Tables 1 and 2), which do not succeed in satisfying the specified design requirements in most of the cases studied.

As regards the 6-storey buildings (Table 3), in the cases of columns with HE300B and HE280B steel cores, the identified optimal retrofit solutions are not only feasible, but are also the most cost-effective ones, outperforming the other two retrofit methods. As already mentioned, all under-designed 6-storey structures are braced frames, with the installed bracings resulting in significantly increased total stiffness and, consequently, in reduced fundamental period for 
these frames. Even though all deficient 6-storey buildings violate the maximum admissible interstorey drift constraint as well, the fundamental period limit is barely exceeded. Hence, a limited strengthening of selected composite columns (with minimal steel caging using $t_{c}=5 \mathrm{~mm}$, $\beta=5 \%$ ) is really effective and beneficial for both interstorey drift and fundamental period criteria (in addition to the structural member capacity criteria defined in Eurocode 4), which explains the success of the cage method in providing the most cost-effective designs for the two particular cases mentioned above. Furthermore, this method manages to determine feasible designs for two more under-designed 6-storey structures with even weaker columns, although the other two retrofit methods suggest more economical solutions for these two cases. Finally, it is observed in Table 3 that the increase in the total retrofit cost for decreasing column section size is considerably smoother in the case of the 6-storey buildings than those observed inTables 1 and 2 for the lower buildings.

\subsection{Jacket Method}

From the results of Tables 1 to 3, it is evident that the jacket method can be effectively applied to a significantly wider range of under-designed buildings than the cage method. In fact, the jacket method manages to provide feasible retrofit solutions for all deficient column cases considered in this section. Moreover, the increase in the total retrofit cost for decreasing column section size is generally much smoother than in the cage method. In all studied cases concerning the seismic retrofit of pure MRFs (i.e. the 2-storey and 4-storey structures), the jacket method provides more cost-effective retrofit solutions than the cage-method. It is indicative that the retrofit of the 2-storey building with HE180B column steel cores by the jacket method requires about the same total equivalent steel mass as the retrofit of the 2-storey building with HE450B column steel cores using the cage method. The jacket method actually succeeds in providing more cost-effective solutions than both other retrofit approaches in the cases of 2-storey buildings having columns with HE500B or HE450B steel cores, as well as in the case of the 4storey building having columns with HE700B steel cores.

As regards the braced frames of the 6-storey buildings examined, the jacket method outperforms the cage method in all cases studied except for the ones with HE300B and HE280B column steel cores. Note also that the jacket method is actually the only approach that is able to provide a feasible retrofit solution for the 6-storey building with the weakest columns (HE220B steel 
cores). This is related to the fact that, while the steel bracings increase the overall stiffness of the building, they do not enhance the columns' moment resistance. Hence, in the case of a braced frame with very weak columns, while the structure is capable of receiving the gravitational loads (self-weight and imposed loads due to typical use), the design bending moments developed in the columns at the Ultimate Limit States exceed the columns' resistance. Hence, their sections need to be adequately strengthened, which can only be achieved using the jacket or the cage method.

In the cases where the same retrofit solution is identified by the optimizer for two different deficient buildings of the same height, it is observed that the total retrofit mass demanded is higher for the building with larger initial column section size. This is due to the way the selected retrofit option is defined, i.e. by specifying only the jacket thickness and the reinforcement diameter. Hence, the actual dimensions of the jacket are related to the respective dimensions of the existing column. This results in larger total jacket concrete volume for larger existing column sections. To reduce the additional retrofit cost for such designs, a finer database with extra, intermediate retrofit options could be provided for the optimizer to choose from.

Compared to the cage method, the jacket method offers retrofit solutions that require more space in the floor plan to be applied. If there are relevant architectural constraints to limit the degree of retrofit invasiveness, these could be taken into account through a penalty function increasing the objective function value proportionally to the additional area covered by the retrofitted column sections. Hence, although such constraints are not considered in the present work, there are ways to effectively deal with these, if needed.

It is worth noting that, with few exceptions, the optimized retrofit solutions of the jacket method use longitudinal steel reinforcement bars with the minimum diameter available in the respective database $(d=12 \mathrm{~mm})$. The optimization algorithm seems to prefer jacket designs with this rebar size, because they exploit the jacket concrete as a low-cost means to increase the distance of the steel rebars from the columns' centroids. Hence, a column's capacity and stiffness can be significantly increased with a proportionally smaller increase in the total retrofit cost. To validate the optimality of the jacket designs determined by the optimization procedure, all optimized solutions with at least one column group having jackets with rebar diameter larger than $12 \mathrm{~mm}$ were further investigated manually. Indeed, for these cases, the most cost-effective feasible retrofits using only rebars with $d=12 \mathrm{~mm}$ were found to have a higher total cost than 
the designs output by the optimizer with larger rebar sizes. Hence, despite the aforementioned advantage of small-size rebars in thick jackets, the optimization algorithm was able to automatically identify certain exceptions, in which more cost-effective retrofit solutions are available using rebars of larger size. As an alternative to jacket designs using rebars with large diameters, a larger number of small-size rebars per side could be utilized, provided that there is adequate space for their installation.

Another interesting observation is that, except for the retrofit of 4-storey MRFs with very weak columns, the optimizer exhibits a general tendency not to strengthen all columns in a retrofit design, but to activate jacketing only for certain column groups each time. The jacketed column groups are not the same in every optimization run performed and can be 1,2,3 or 4, depending on the features of the particular retrofit problem at hand. This makes it difficult to manually identify the optimized retrofit solution in each case considered and emphasizes the effectiveness and usefulness of the presented optimization procedure.

\subsection{Bracings Method}

The installation of bracings in a MRF is a particularly effective method to reduce its fundamental period, leading to decreased ductility demands, which are imposed in this work through the targeted top displacement for the pushover analysis. This effect is confirmed by the results of Tables 1 and 2, which show that the optimization algorithm was able to identify feasible retrofit designs for all 2-storey and 4-storey under-designed MRFs using only the smallest available L-section for the bracings at the corner bays of all building sides. When the results of Table 1 (2-storey MRFs) and Table 2 (4-storey MRFs) are examined separately, it can be observed that, although the same bracing section is utilized in all retrofit solutions, deficient buildings with smaller column section sizes require less steel mass to be retrofitted with the bracings method than buildings with larger column section sizes. Indeed, smaller column section dimensions lead to increased need for steel mass due to longer bracings, but also to reduced need for steel mass due to smaller supporting frame dimensions. The savings in steel mass for the supporting frame are larger, which explains the noticeable reduction in the total retrofit cost for decreasing column section size.

As regards the under-designed 6-storey buildings (Table 3), optimized retrofit solutions can be provided for 3 cases (with HE300B to HE260B steel cores) by replacing the bracings at all 
building sides with stronger ones. Again, as explained above, smaller column section sizes lead to reduced total retrofit costs. Nevertheless, for the 2 buildings with the weakest columns (HE240B and HE220B steel cores), the bracings method is unable to provide feasible retrofit solutions. For these 2 cases, feasible and possibly affordable retrofit designs can only be obtained by keeping the initial bracings and strengthening 3 column groups using the jacket method (Table 3).

It is of particular interest that none of the identified optimal retrofit designs using the bracings method is a mixed solution, i.e. a retrofit design specifying the replacement of bracings combined with the strengthening of columns using either the cage or the jacket method. This is a very convenient outcome, because, unless the use of bracings is prohibited, a designer can manually determine a cost-effective retrofit solution without the need to run a time-demanding optimization procedure. More specifically, once the bays where bracings can be installed are defined, a designer only needs to check the building performance using the available bracings' sections from the smallest size to larger ones until a feasible design is determined. Especially in retrofitting relatively slender buildings, the use of bracings can be very advantageous in the framework of either a manual or an automatic optimization procedure.

However, when either bracing sections are increased or bracings at new locations are installed in a structure, special care must be taken for columns, which need to be able to carry concentrated shear forces at the connections with bracings. Despite the fact that the building's fundamental period is reduced when larger or additional bracings are installed leading to reduced ductility demands, deficient columns may fail and cause local collapse during pushover analysis before the structure reaches the targeted top displacement. In such cases, column strengthening methods need to be applied in combination with the bracings method to achieve the desired structural system performance. This need was not encountered in any retrofit case studied in the present paper.

\section{Concluding remarks}

Today's stock of old structures that are under-designed with respect to current design codes is rather large. Improving the structural behaviour and performance of such structures requires the development and validation of effective retrofit approaches, but also vast budgets for their application in practise. The aim of the present work is to comparatively assess the cost- 
effectiveness of a number of seismic retrofit approaches for deficient buildings with steelconcrete composite columns, in order to facilitate the selection of the economically most viable intervention depending each time on the particular case at hand.

Three different seismic retrofit approaches are studied in this paper. Reinforced concrete jacketing and concrete-covered steel caging are two local retrofit approaches that aim in indirectly upgrading structural performance at the global system level through individual column strengthening. The installation of steel bracings at selected bays of a structure is a global retrofit approach that focuses directly on enhancing system resistance by adding new structural elements. These 3 retrofit approaches were compared on a 'fair', objective basis using a specially developed structural optimization procedure to automatically determine the most costeffective retrofit solution for each case studied, without relying on the capabilities, experience and subjectivity of a particular designer. All assessed retrofit approaches were found to be effective in improving structural performance, but none of the approaches was found to be the most suitable and cost-effective for all cases of deficient buildings considered.

Based on the retrofit solutions obtained from a total number of 120 optimization runs for 30 cases of under-designed 2-storey, 4-storey and 6-storey buildings, the following main conclusions can be drawn regarding the advantages and relative cost-effectiveness of each of the 3 retrofit approaches studied:

- For lightly under-designed buildings (i.e. the total interstorey stiffness deficiency is up to about $30 \%$ that of the code-conforming reference building), the installation of concretecovered steel cages at selected or even all composite columns appears to be the most tractable retrofit approach. When limited additional strength and stiffness are required, this approach provides retrofit solutions that are simultaneously the most cost-effective and least aesthetically intervening, improving also the confinement of the existing concrete of the composite columns.

- In the case of higher requirements for additional column capacity and stiffness of underdesigned buildings, the installation of reinforced concrete jackets at selected or even all composite columns provides more cost-effective retrofit solutions. This approach exploits the jacket thickness of the retrofitted element, in order to place reinforcing steel bars at large distances from the section's centroid and ensure this way their increased contribution to the column's stiffness and flexural capacity. This is the only approach that managed to provide 
feasible retrofit solutions for all cases studied in this paper, from lightly to overly underdesigned buildings (i.e. with total interstorey stiffness deficiency even up to $80 \%$ that of the code-conforming reference building). Nevertheless, there are technical and practical limitations associated with the selection of jacket thicknesses, therefore there are also restrictions in the applicability and effectiveness of this retrofit approach.

- The installation of adequate steel bracings seems to be often necessary in overly underdesigned buildings. The weak columns of such non-retrofitted buildings result in low stiffness and rather high, unacceptable fundamental periods. Bracings change the structural system and its behaviour, effectively shift its fundamental period, but do not necessarily alleviate the deficient composite columns. Therefore, if the capacities of the columns do not suffice, bracings need to be combined with one of the two aforementioned column strengthening approaches (jacketing or caging). If the columns' capacities suffice, the installation of adequate bracings without any other additional intervention can decisively improve a composite building's performance and provide the most cost-effective retrofit solution.

\section{References}

[1] Tassios, T. P. The mechanics of column repair with a reinforced concrete jacket. In Proc. 7th European Conference on Earthquake Engineering, Athens, September 1982.

[2] Bett, B. J., Klingner, R. E., \& Jirsa, J. O. (1988). Lateral load response of strengthened and repaired reinforced concrete columns. Structural Journal, 85(5), 499-508. DOI: 10.14359/9226

[3] Rodriguez, M., \& Park, R. (1991). Repair and strengthening of reinforced concrete buildings for seismic resistance. Earthquake Spectra, 7(3), 439-459. DOI: 10.1193/1.1585636

[4] Chalioris, C. E., Thermou, G. E., \& Pantazopoulou, S. J. (2014). Behaviour of rehabilitated RC beams with self-compacting concrete jacketing-Analytical model and test results. Construction and Building Materials, 55, 257-273. DOI: 10.1016/j.conbuildmat.2014.01.031

[5] Júlio, E. N., Branco, F. A., \& Silva, V. D. (2005). Reinforced concrete jacketing-interface influence on monotonic loading response. ACI Structural Journal, 102(2), 252.

[6] Nasersaeed, H. (2011). Evaluation of behavior and seismic retrofitting of RC structures by concrete jacket. Asian journal of applied sciences, 4(3), 211-228. DOI: 10.3923/ajaps.2011.211.228

[7] Takeuti, A. R., de Hanai, J. B., \& Mirmiran, A. (2008). Preloaded RC columns strengthened with highstrength concrete jackets under uniaxial compression. Materials and structures, 41(7), 1251-1262. DOI: $10.1617 / \mathrm{s} 11527-007-9323-0$

[8] Tsonos, A. D. G. (2010). Performance enhancement of R/C building columns and beam-column joints through shotcrete jacketing. Engineering Structures, 32(3), 726-740. DOI: 10.1016/j.engstruct.2009.12.001

[9] Vandoros, K. G., \& Dritsos, S. E. (2006). Axial preloading effects when reinforced concrete columns are strengthened by concrete jackets. Progress in Structural Engineering and Materials, 8(3), 79-92. DOI: $10.1002 /$ pse. 215

[10] Campione, G., Fossetti, M., Giacchino, C., \& Minafò, G. (2014). RC columns externally strengthened with RC jackets. Materials and structures, 47(10), 1715-1728. DOI: 10.1617/s11527-013-0146-x

[11] Minafò, G., Di Trapani, F., \& Amato, G. (2016). Strength and ductility of RC jacketed columns: A simplified analytical method. Engineering Structures, 122, 184-195. DOI: 10.1016/j.engstruct.2016.05.013 
[12] Thermou, G. E., Papanikolaou, V. K., \& Kappos, A. J. (2014). Flexural behaviour of reinforced concrete jacketed columns under reversed cyclic loading. Engineering Structures, 76, 270-282. DOI: 10.1016/j.engstruct.2014.07.013

[13] Lampropoulos, A. P., \& Dritsos, S. E. (2011). Modeling of RC columns strengthened with RC jackets. Earthquake Engineering \& Structural Dynamics, 40(15), 1689-1705. DOI: 10.1002/eqe.1109

[14] Navarrete, B. A. O., Guerrero, J. M. J., Juana, M. D. L. C. T., Soberón, G., \& Díaz, M. J. (2016). Influence of RC jacketing on the seismic vulnerability of RC bridges. Engineering Structures, 123, 236-246. DOI: 10.1016/j.engstruct.2016.05.029

[15] Papanikolaou, V. K., Stefanidou, S. P., \& Kappos, A. J. (2013). The effect of preloading on the strength of jacketed R/C columns. Construction and Building Materials, 38, 54-63. DOI: 10.1016/j.conbuildmat.2012.07.100

[16] Choi, E., Chung, Y.-S., Park, K., \& Jeon, J.-S. (2013). Effect of steel wrapping jackets on the bond sthrenth of concrete and the lateral performance of circular RC columns. Engineering Structures, 48, 43-54. DOI: 10.1016/j.engstruct.2012.08.026

[17] Lin, M.-L., Chen, P.-C., Tsai, K.-C., Yu, Y.-J., \& Liu, J.-G. (2010). Seismic steel jacketing of rectangular RC bridge columns for the mitigation of lap-splice failures. Earthquake Engineering and Structural Dynamics, 39, 1687-1710. DOI: 10.1002/eqe.1003

[18] Su, R., Cheng, B., Wang, L., Siu, W., \& Zhu, Y. (2011). Use of bolted steel plates for strengthening of reinforced concrete beams and columns. IES journal Part A: Civil and Structural Engineering, 4 (2), 5568. DOI: $10.1080 / 19373260.2011 .567816$

[19] Haskett, M., Oehlers, D. J., \& Mohamed Ali, M. (2010). Design for moment redistribution in RC beams retroffited with steel plates. Advances in Structural Engineering, 13 (2), 379-391. DOI: 10.1260/13694332.13.2.379

[20] Adam, J. M., Ivorra, S., Pallarés, F. J., Giménez, E., \& Calderón, P. A. (2009). Axially loaded RC columns strengthened by steel caging. Finite element modelling. Construction and Building Materials, 23(6), 22652276. DOI: 10.1016/j.conbuildmat.2008.11.014

[21] Campione, G. (2012). Load carrying capacity of RC compressed columns strengthened with steel angles and strips. Engineering Structures, 40, 457-465. DOI: 10.1016/j.engstruct.2012.03.006

[22] Garzón-Roca, J., Ruiz-Pinilla, J., Adam, J. M., \& Calderón, P. A. (2011). An experimental study on steelcaged RC columns subjected to axial force and bending moment. Engineering Structures, 33(2), 580-590. DOI: 10.1016/j.engstruct.2010.11.016

[23] Montuori, R., \& Piluso, V. (2009). Reinforced concrete columns strengthened with angles and battens subjected to eccentric load. Engineering Structures, 31(2), 539-550. DOI: 10.1016/j.engstruct.2008.10.005

[24] Nagaprasad, P., Sahoo, D. R., \& Rai, D. C. (2009). Seismic strengthening of RC columns using external steel cage. Earthquake Engineering \& Structural Dynamics, 38(14), 1563-1586. DOI: 10.1002/eqe.917

[25] Rodriguez, M., \& Park, R. (1991). Repair and strengthening of reinforced concrete buildings for seismic resistance. Earthquake Spectra, 7(3), 439-459. DOI: 10.1193/1.1585636

[26] Uy, B. (2002). Strength of reinforced concrete columns bonded with external steel plates. Magazine of Concrete Research, 54(1), 61-76. DOI: 10.1680/macr.2002.54.1.61

[27] Kawamata, S., \& Ohnuma, M. (1981). Strengthening effect of eccentric steel braces to existing reinforced concrete frames. In 7WCEE Conference, Proceedings of 2nd Seminar on Repair and Retrofit of Structures.

[28] Badoux, M., \& Jirsa, J. O. (1990). Steel bracing of RC frames for seismic retrofitting. Journal of Structural Engineering, 116(1), 55-74. DOI: 10.1061/(ASCE)0733-9445(1990)116:1(55)

[29] Maheri, M. R., \& Sahebi, A. (1997). Use of steel bracing in reinforced concrete frames. Engineering Structures, 19(12), 1018-1024. DOI: 10.1016/S0141-0296(97)00041-2

[30] Ghobarah, A., \& Abou-Elfath, H. A. (2001). Rehabilitation of a reinforced concrete frame using eccentric steel bracing. Engineering structures, 23(7), 745-755. DOI: 10.1016/S0141-0296(00)00100-0

[31] Maheri, M. R., \& Akbari, R. (2003). Seismic behaviour factor, R, for steel X-braced and knee-braced RC buildings. Engineering structures, 25(12), 1505-1513. DOI: 10.1016/S0141-0296(03)00117-2

[32] Youssef, M. A., Ghaffarzadeh, H., \& Nehdi, M. (2007). Seismic performance of RC frames with concentric internal steel bracing. Engineering Structures, 29(7), 1561-1568. DOI: 10.1016/j.engstruct.2006.08.027

[33] Mazzolani, F. M. (2008). Innovative metal systems for seismic upgrading of RC structures. Journal of Constructional Steel Research, 64(7-8), 882-895. DOI: 10.1016/j.jcsr.2007.12.017

[34] Di Sarno, L., \& Elnashai, A. S. (2009). Bracing systems for seismic retrofitting of steel frames. Journal of Constructional Steel Research, 65(2), 452-465. DOI: 10.1016/j.jcsr.2008.02.013

[35] Güneyisi, E. M. (2012). Seismic reliability of steel moment resisting framed buildings retrofitted with buckling restrained braces. Earthquake Engineering \& Structural Dynamics, 41(5), 853-874. DOI: 10.1002/eqe. 1161 
[36] Sutcu, F., Takeuchi, T., \& Matsui, R. (2014). Seismic retrofit design method for RC buildings using buckling-restrained braces and steel frames. Journal of Constructional Steel Research, 101, 304-313. http://dx.doi.org/10.1016/j.jcsr.2014.05.02

[37] Rahimi, A., \& Maheri, M. R. (2018). The effects of retrofitting RC frames by X-bracing on the seismic performance of columns. Engineering Structures, 173, 813-830. DOI: 10.1016/j.engstruct.2018.07.003

[38] Lagaros, N.D. (2014). A general purpose real-world structural design optimization computing platform, Structural and Multidisciplinary Optimization, 49, 1047-1066. DOI: 10.1007/s00158-013-1027-1

[39] Lagaros, N.D. (2018). The environmental and economic impact of structural optimization, Structural and Multidisciplinary Optimization, 58(4), 1751-1768. DOI: 10.1007/s00158-018-1998-z.

[40] Mavrokapnidis, D., Mitropoulou, Ch.Ch., Lagaros, N.D. (2019). Environmental assessment of cost optimized structural systems in tall buildings, Journal of Building Engineering, 24, 100730. DOI: 10.1016/j.jobe.2019.100730.

[41] Papavasileiou, G.S., Charmpis, D.C. (2016). Seismic design optimization of multi-storey steel-concrete composite buildings, Computers and Structures, 170, 49-61. DOI: 10.1016/j.compstruc.2016.03.010.

[42] Papavasileiou, G.S., Charmpis, D.C. (2020). Earthquake-resistant buildings with steel or composite columns: Comparative assessment using structural optimization, Journal of Building Engineering, 27, 100988. DOI: 10.1016/j.jobe.2019.100988

[43] Comité Européen de Normalisation. (2003). Eurocode 4: Design of Composite Steel and Concrete Structures.Brussels, Belgium: Comité Européen de Normalisation (CEN).

[44] Mazzoni S, McKenna F, Scott M, Fenves GL. Open System for Earthquake Engineering Simulation, OpenSees Command Language Manual, PEER Center, California, USA, 2006.

[45] Papadrakakis, M., Lagaros, N.D., Thierauf, G., Cai, J. (1998). Advanced solution methods in structural optimization based on evolution strategies, Journal of Engineering Computations, 15(1), 12-34. DOI: 10.1108/02644409810200668.

[46] Comité Européen de Normalisation. (2003). Eurocode 3: Design of Steel Structures (ENV 1993).Brussels, Belgium: Comité Européen de Normalisation (CEN).

[47] American Society of Civil Engineers. (2006). Seismic Rehabilitation of Existing Buildings, A.S.C.E. Standard A.S.C.E./S.E.I. 41-06, including Supplement No. 1. Reston, Virginia, U.S.A.: American Society of Civil Engineers.

[48] Federal Emergency Management Agency. (2005). Improvement of Nonlinear Static Seismic Analysis Procedures (FEMA-440). WashingtonD.C., U.S.A.: Federal Emergency Management Agency.

[49] Goel, R. K., and Chopra, A. K. (1997). Period formulas for moment-resisting frame buildings. Journal of Structural Engineering, 123 (11), 1454-1461. DOI: 10.1061/(ASCE)0733-9445(1997)123:11(1454) 